University of Louisville

ThinkIR: The University of Louisville's Institutional Repository

$12-2012$

\title{
Institutionalism to contextualism : modifying the institutional theory of art into a historical/cultural contextualist account.
}

Stephanie Ann Coffman

University of Louisville

Follow this and additional works at: https://ir.library.louisville.edu/honors

Part of the History of Art, Architecture, and Archaeology Commons, and the Philosophy Commons

\section{Recommended Citation}

Coffman, Stephanie Ann, "Institutionalism to contextualism : modifying the institutional theory of art into a historical/cultural contextualist account." (2012). College of Arts \& Sciences Senior Honors Theses. Paper 1.

http://doi.org/10.18297/honors/1

This Senior Honors Thesis is brought to you for free and open access by the College of Arts \& Sciences at ThinkIR: The University of Louisville's Institutional Repository. It has been accepted for inclusion in College of Arts \& Sciences Senior Honors Theses by an authorized administrator of ThinkIR: The University of Louisville's Institutional Repository. This title appears here courtesy of the author, who has retained all other copyrights. For more information, please contact thinkir@louisville.edu. 
“Institutionalism to Contextualism: Modifying the Institutional Theory of Art into a Historical/Cultural Contextualist Account”

\author{
By \\ Stephanie Ann Coffman
}

\author{
Submitted in partial fulfillment of the requirements \\ for Graduation summa cum laude
}

University of Louisville

December, 2012 


\section{I: Introduction}

Most philosophers of art would agree that the question "What is art?" has yet to be satisfactorily answered. This isn't, of course, due to a lack of bold attempts by many bright minds to provide an affirmative answer but, instead, due to the inadequacies that each answer has been shown to have. However, I do believe that the proposed answers have all, for the most part, provided insightful arguments and are often very well suited to satisfy a part of the question; there are, nevertheless, none that answer the question entirely. Now, while I have little intention to bring an end to an important philosophical debate, I will argue that the pieces to this philosophical puzzle are all present for the most part; they just need to be put together.

With this in mind, I attempt here to formulate a viable account of art utilizing an already well-defined theory as a framework, George Dickie's Institutional Theory of Art, as formulated in $1974 .{ }^{1}$ I will first offer an extensive discussion of all aspects of the theory and then address the chief criticisms. These criticisms are significant but do not show the theory to be unsound, so here I will defend the theory against them. Finally, I will propose a modification based on the one criticism that reveals an insurmountable flaw in Dickie's theory. I will argue that the only way to overcome this flaw is to incorporate a fundamentally historical/cultural contextualist definition of art. This shall result in a new, much more attractive, theory and bring us closer to answering the question "What is art?” in its entirety.

\section{II: The Institutional Theory of Art}

\footnotetext{
${ }^{1}$ For a summary of George Dickie's formulations of an institutional definition of art (1969, 1971, 1974, and 1984), see his "The Institutional Theory of Art" in Carroll (2000). For the original formulations, see Dickie (1969), Dickie (1971), Dickie (1974), and Dickie (1984).
} 
The institutional theory of art is a procedural account of art which argues that "works of art" are art on account of their position occupied within an institutional context. The theory has been revamped many times but all versions of Dickie’s theory approach art in a classificatory sense. That is, they take a value-neutral approach to art; art vs. non-art opposed to valuable art vs. invaluable/less valuable art. In addition, all versions stand as intermediaries between treating art as an open or closed concept. They deny, as advocates of art as an open concept do, that art has any sort of "internal" essence- that there isn't one feature common to all works of art that explains why they are works of art. Their insight is that one can accept that art has no internal essence but that art can still be defined, not by an internal essence, but by listing, as proponents of art as a closed concept do, necessary and jointly sufficient conditions. They do this by taking an externalist approach: they argue that whether something is considered art is determined by factors external to the piece, such as context, opposed to intrinsic features, such as brushstrokes and beauty.

The version of Dickie's theory I focus on is below and this version, in my view, is almost entirely sufficient to stand as a proper theory of what makes something a work of art.

A work of art in the classificatory sense is (1) an artifact (2) a set of the aspects of which has had conferred upon it the status of candidate for appreciation by some person or persons acting on behalf of a certain social institution (the artworld). ${ }^{2}$

\footnotetext{
${ }^{2}$ See Warburton (2003), 95.
} 
Before addressing the criticisms and the proposal for modification, it is imperative to understand the institutional theory itself. ${ }^{3}$ The first condition in Dickie's theory is that a work of art is an artifact. The status of artifactuality can be achieved in two ways. The first way is to be crafted in one traditional way or another and the second way is to have the status of artifactuality conferred upon the work by a member of the artworld. Note that the second way of acquiring artifactuality, through conferral, was specified in the theory in order to account for "found art," in which no traditional crafting occurs. ${ }^{4}$

The second condition of the theory, as stated by Dickie, is that, "art is a set of the aspects of which has had conferred upon it the status of candidate for appreciation by some person or persons acting on behalf of a certain social institution (the artworld).” It is first important to mention that Dickie's use of the word "status" is entirely neutral. The use of the word "status" is usually in regard to "status symbols," which suggests a certain "high status.” However, Dickie’s theory is only concerned with art in a classificatory sense, art vs. non-art. Nevertheless, an artifact has the status of candidate for appreciation conferred upon it, by some member(s) of the artworld, via a process not unlike a christening ceremony. Now, the term "christening ceremony" suggests a formal process but the practice of conferral can be exceptionally simple, such as an artist treating an object a certain way or an object being put on exhibition as a candidate for appreciation. With this in mind, it is clear that a work being considered "art" is only a product of the way that the work is treated, opposed to the features of the work itself; again, the theory takes an externalist approach. Also, it is only a set of the aspects, not the whole artifact, of which has

\footnotetext{
${ }^{3}$ See Warburton (2003), 86-112, Dickie (1974), or Carroll (2000), 93-107.

${ }^{4}$ For examples of "found art," see "Institutional Contexts" in Warburton (2003), 86, 101. It includes discussions of pieces such as A Real Work of Art (1993) by Mark Wallinger, who conferred the status of candidate for appreciation on a racehorse, and Damien Hirst's $A$ Thousand Years (1990), the status was conferred on a rotting cow's head, and The Physical Impossibility of Death (1989), the status was conferred on a dead shark in formaldehyde.
} 
had conferred upon it the status of candidate for appreciation; insinuating that some aspects, such as the frame, could be removed without affecting the work.

The concept of a work being a "candidate" for appreciation is an essential feature of the theory. According to Dickie, despite a work’s presentation as a candidate for appreciation, an object can fail to be appreciated; in this case it is failed art. To illustrate this concept, consider "anxious objects." ${ }^{5}$ They are modern creations designed to raise uncertainties as to whether they are art and are often shunned by the public. An example is My bed (1998) by Tracey Emin. The piece is her own bed containing her dirty clothes, empty vodka bottles, and other bedroom clutter. Now, I do not believe that her piece possesses anything of aesthetic or artistic merit. However, it has had the status of candidate for appreciation conferred upon it. So, in my case, Tracey Emin's piece fails to be appreciated; irrespectively, it is still art.

Now, in regard to the artworld, it is not, according to Dickie, an assembly of exclusive art dealers or gallery organizers - it is not an elitist concept at all. Instead, it is anyone who considers himself or herself as a member of it; it is in effect a cultural construction. This means that it has been made into what it is by members of society and is subject to modification as the members of society change, mentally (views) or physically (moving in or out of a given population). To explain this point, Dickie has stated that an artworld contains literature, painting, sculpture, etc. but dog shows are usually not considered to fit within the cultural construction of the artworld; if, however, the history of culture had been a little different, then the artworld would also be different and may include dog shows. This portion of theory is based on the fact

\footnotetext{
${ }^{5}$ For a discussion of "anxious objects," see Paul N. Humble, "Anti-art and The Concept of Art," in Smith (2002), 244-252. Examples of "anxious objects" include works such as Fountain (1917), which is a urinal, and Comb (1916), a small iron comb inscribed with an insensible sentence, both by Duchamp.
} 
that there is an element of volatility in every cultural construction; because they are the result of people's behavior over time, they are not static, inflexible assemblies. ${ }^{6}$

I will now discuss how the conferral of the status of candidate for appreciation demonstrates how the theory focuses on relational properties. For Dickie, the feature(s) that makes something a work of art is not a visible feature(s) of the work itself; it is its relation to a particular set of social practices. This suggestion, that what makes a work considered "art” is not visible, was actually made by Arthur Danto. He suggested that it is theory, opposed to a visible element/intrinsic feature, which makes something a work of art. An example to clarify this would be Warhol's Brillo Boxes. It is consumer-product imagery at its best; it is a series of sculptures, painted and silkscreened plywood boxes, which are more or less identical to Brillo soap pad boxes. Danto noted that the difference between an everyday Brillo box, such as one in a kitchen, and Warhol's work is that Warhol's embodies a certain theory of art. Thus, despite the fact that they are largely visually indiscernible ${ }^{7}$, the theory of art underlying Warhol's piece, the "artistic intention”, separates it from the everyday object. ${ }^{8,9}$

\section{III: Criticisms of the Institutional Theory of Art}

Now that I have addressed the main ideas behind Dickie's theory, I will discuss the criticisms. One criticism of Dickie's theory is that it trivializes art; it is thought to "let too much in.” I will not deny the validity of this criticism. It is true that anything, whether it is a blade of grass or an

\footnotetext{
${ }^{6}$ See Dickie in Carroll (2000), 100.

${ }^{7}$ Warhol's Brillo boxes are somewhat bigger than their grocery store counterparts and made of plywood opposed to cardboard.

${ }^{8}$ For the full discussion of Warhol's Brillo Boxes (1964) by Danto see Cahn (2008), 422-423. An additional article in which Danto discusses the difference between artworks and what he regards as mere "real things" can be seen in "The Transfiguration of the Commonplace" Danto (1974), 139-48.

${ }^{9}$ An additional example that offers the same situation as Warhol's Brillo Boxes (1964), as in being separated from its everyday counterpart by a certain theory of art, is Duchamp's Fountain (1917). The work is an ordinary porcelain urinal but art on account of the artistic intention associated with it.
} 
elaborate sculpture, might satisfy the two requirements to be deemed a work of art. It isn't the requirements, the status of artifactuality and candidate for appreciation, that are the issue but instead, how these statuses can be acquired. Both statuses can be attained through the conferral of that status by a member of the artworld and, according to Dickie, the artworld consists of anyone who considers himself or herself a member of it. Thus, anything can become a work of art because anything can acquire the required statuses. Fortunately, the institutional theory accounts for this. It allows that a work can acquire the status of candidate for appreciation and, if the conferral was unwarranted, fail to be appreciated. Thus, despite that it is still art, the work is failed art. The criticism, that it allows too much to become art, can be viewed as strength of the theory. Unlike functionalist, prescriptive theories, the institutional theory does not foreclose on creativity. ${ }^{10}$ Dickie's approach does not impose any cramping conditions on what can be art and thus does not, unlike closed concepts, destroy our ability to redefine art or allow it to evolve in genuinely novel ways.

A second criticism concerns so-called outsider art, a category of art produced well outside of anything that could be regarded as the art world. ${ }^{11}$ An example would be the works in Walter Morgenthaler’s A Psychiatric Patient as Artist (1921). It contains the "works” of one of his patients, who seemed to have created his "art" without any concept of art or the artworld. Of course, “outsider art” isn't a term that only concerns works produced by the mentally ill; if an elephant had a paintbrush and made a series of brushstrokes, brilliant or not, that work might be considered outsider art. Nonetheless, the criticism is that the theory does not allow the works to

\footnotetext{
${ }^{10}$ Approaching art in a prescriptive way, which is not what Dickie's theory does, means that specific standards/rules have been established that an object must meet in order to be art. Thus, prescriptive theories make it to where anything not meeting the defined standards is completely denied the possibility of being considered art; they make art a closed concept, which is a concept where all of the necessary conditions that are required to include something within the given concept can be noted.

${ }^{11}$ For a discussion on the history as well as the reception of outsider art, see Rhodes (2000).
} 
be considered art in their own right, which is valid. The theory does not allow outsider works to be art until a member of the artworld confers the status of candidate for appreciation upon them. The so-called "outsiders" are working outside of any understanding of the artworld; thus, the features, most often, found to be worthy of commendation were not intentional. They were unplanned or accidental and their newfound significance is the result of changes in social practices, such as popular views/opinions on art. ${ }^{12}$ It must be considered that the outsider themselves, because they are wholly outside of the artworld and possibly unaware of the existence of an art institution whatsoever, would not consider what they have done art. The lack of artistic intention makes it only logical for the works to become art when someone, who is aware of the standing art institution, confers that status upon it.

I have demonstrated that the last two criticisms, while valid, do not make the theory unsound. Nonetheless, there is another criticism to consider; I will not defend the theory against it but instead I will propose a modification to the theory to eliminate the source of the problem. The criticism is that the members of the artworld who confer the status of candidate for appreciation must have reasons for the conferral, or their judgment is utterly arbitrary. If there are reasons, however, those reasons would then constitute a theory of what makes something art in a prescriptive sense, specifying a set of necessary conditions, and as such that theory would no longer be an institutional theory. And if there were no reasons the conferral would be, as stated, an arbitrary process. This would result in art losing its value because there would be no reason for making one thing, rather than another, a candidate for appreciation and thus art. Dickie has refuted the idea that there is a set of reasons dictating what works are granted the status of candidate for appreciation. It undermines his theory of something being art because it has the

${ }^{12}$ See Warburton (2003), 101-108. 
status of candidate for appreciation; the status wouldn't be why something was considered art, the reasons for the conferral of that status would be. The idea that it is an arbitrary practice is actually more consistent with Dickie's theory; he does not want to limit when the status can be conferred. Unfortunately, if it is a whimsical process, the question arises to why we should even be interested in what art is.

\section{IV: Modifying the Institutional Theory of Art}

It is illogical to think that there is no reason for a work to have had the status of candidate for appreciation conferred upon it. This reveals the need for modification, which I will now offer. The proposed modification is that there are reasons. More specifically, that the conferral of the status is based on the recognition of specific intrinsic properties; or rather that there is an interplay of external and intrinsic features that offers the reasons for the conferral of the status of candidate for appreciation. These properties are the components of a dynamic, "isolated" art theory (more on this below). Thus, there are sets of intrinsic features, which are specified by a given theory of art, which are used to determine what is to have the status of candidate for appreciation. The theories, that specify the intrinsic features necessary for a work to acquire the status of candidate for appreciation, are a product of the historical (the events of the past leading up to the current time) and cultural (current beliefs, customs, practices, etc.) context. Thus, they are subject to change and have primary reference to their particular historical/cultural backdrop - they are "isolated" to this context. Hence, more than one theory can exist at a time since there is more than one backdrop subsisting simultaneously. A theory for a particular location/time only stands as an accurate, relevant theory until the historical and cultural context changes and prompts the development of a different theory based on the alterations of views. 
It is important to note that my account of art is still based on the framework of Dickie's theory; a work of art still must be an artifact, achieved through crafting or conferral of that status, and it still must have the status of candidate for appreciation. The difference is that the work had conferred upon it the status of candidate for appreciation because of the dynamic, "isolated" art theory in place. Thus, it is the salvageable elements of Dickie's theory, with the addition of my modification, which gives the new account of art below:

A work of art in the classificatory sense is (1) an artifact (2) a set of the aspects of which has had conferred upon it the status of candidate for appreciation by some person or persons acting on behalf of a certain social institution (the artworld). The reasons for the conferral are based on the relevant dynamic and isolated art theory, according to which art is constituted of specific intrinsic properties, that is a product of the historical and cultural context at that specific time and place (the extrinsic properties of interest).

Before defending my modification, I will first discuss how the art theories that are operative in a specific cultural/historical context are devised. My proposed theory has a very specific order; extrinsic influences such as societal forces dictate, by affecting artmaking practices, what intrinsic properties are commonly found throughout works for a given context. Those intrinsic features constitute an implicit theory of what is art and that theory is utilized to determine what works attain the status of candidate for appreciation. ${ }^{13}$ Because it is the intrinsic features that constitute the theories, the works must be produced, with their common intrinsic

\footnotetext{
${ }^{13}$ I approach the concept of a "theory of art" in the same way that Danto and Dickie approach it; that a theory of art is a set of biases or prejudices that a given culture holds that identifies what is and what is not art.
} 
features, prior to the isolated theory of art being articulated. When the works are recognized at a particular time and location as a "set," a product of a common practice in regard to the display of particular intrinsic properties and that have been affected by the same extrinsic influences, a theory of art can be defined. Once a theory of art has been articulated, the theory can be utilized to determine if other works, produced prior to or after the theory was defined, are qualified for the status of candidate for appreciation in that context.

It is important to mention that the problem of closing the concept of art by defining it via necessary and specific conditions is not an issue with this modification. This is because the theories of art, with their constituent sets of intrinsic properties, used by individuals to confer the status of candidate for appreciation are isolated and dynamic theories. When I state that the theories are isolated, I mean that they are unique to their specific time/location and its respective historical and cultural backdrop. Thus, because more than one historical and cultural context subsists at a given time, that there can exist, simultaneously, more than one specific art theory. The theories are dynamic, able to change over time, because the elevation/praise of a particular theory's constituent intrinsic features is a result of the social practices, beliefs, customs etc. of its respective backdrop and these things are certainly subject to variation. In other words, a theory of art for a specific location can "expire" after a certain period of time as societal forces prompt the theory to be modified. A new theory arises from the old one and it now determines "what is art.” So, extrinsic features, the historical/cultural context for a location at a particular time, control what intrinsic features are necessary for identifying an object as a work of art; there is not a single, universal set of features and the sets are not static. Thus, the concept of art isn't closed; indeed, art has no single essence. 
As stated, Dickie dismisses the idea that the conferral of the status of candidate for appreciation involves the recognition of particular intrinsic features. However, there is evidence to the contrary. When looking at works considered art in particular contexts, there are clear sets of widespread intrinsic properties. To provide some specific examples, I will explore two art movements. Art movements represent periods in which there is a clear prominence of particular intrinsic features. The fact that, as a society, we have even demarcated individual art movements is important to my argument. It helps support the idea that during particular times there are dominant intrinsic features and thus, operative definitions of art. People have clearly recognized the existence of common intrinsic features in specific contexts, making it impossible to deny their existence, if they are willing to group works together under a common heading. The movements represent the isolated/dynamic art theories to which I have been referring.

The first example is Fauvism, which flourished in France from 1898-1906. Fauvism was a movement in painting and was characterized by bold distortions and the use of unmixed colors, often applied directly from the tube, leaving it thick, smeared, and almost violent looking. Expression was the fundamental goal; line, brushwork, and color were all used with the intention of expression opposed to pure representation. The followers of the movement wanted to break away from the trends that had been in place since the Renaissance and get away from the realistic/representational portrayals that dominated current practices. Thus, the subject matter, while still traditional, such as landscapes, cityscapes, portraits, etc., was always distorted or portrayed in an unnatural fashion through unrealistic colors and shaping. ${ }^{14}$

It is of utmost importance to see that I just detailed what the theory of art was surrounding Fauvism. I specified the time period, 1898 to 1906, and the location, France. I

\footnotetext{
${ }^{14}$ See Turner (2000), 173-77.
} 
indicated the historical and cultural context, that there had been a set of "pictorial conventions" in place since the Renaissance and a group of French artists, tired of the conventions, were ready to rebel against the type of works popularized by the impressionists. Then, I specified the intrinsic features characteristic of works considered art for the given context. Most importantly, I illustrated that an art theory, with specific intrinsic features, products of the historical and cultural context (that were also specified), for a particular time and location can be detailed. The art theory, of course, would be the reason behind which a particular work, presented in that particular context, had the status of candidate of appreciation conferred upon it.

Nonetheless, the details of the Fauvist movement that I just gave were clearly deduced after the works associated with the movement had been produced and analyzed; the theories are defined in retrospect. In fact, it can almost be considered that, like with the "family" resemblance theory I discuss below, there are a set of "paradigm works" associated with each theory; works that helped define the theory in the first place. Nonetheless, continuing with Fauvism, I will discuss a piece from the movement itself. The painting is called The Joy of Life (1906) and the artist is Henri Matisse. It depicts an outdoor scene, a recognizable but not realistic landscape, with a number of nude figures throughout. The people are simplistic, recognizable as figures but with little detail, and different colors, some are pink and some are green. The trees also vary in color; some all green and others green with orange leaves. The sky is orange and almost indiscernible from the yellow ground, which is only recognizable by the patches of orange, purple, and green grass. Most of the lines are curved, giving a clear feeling of movement. It is important to note, although evident, that many of the characteristic features of the Fauvist movement I discussed previously are found in this piece. It is of a landscape/ bourgeois leisure, there is distortion, an unnatural use of color, unmixed colors, etc. The artist, Matisse, was 
actually considered the leader of the Fauves and his works undoubtedly helped define the theory surrounding the movement. However, imagine that the piece was just recently discovered and the only thing known about the work is that it was produced in France between 1898 and 1906. It is clear that the work is eligible for the status of candidate for appreciation when the context of its presentation is considered. It reflects the artmaking practices, contains the recognizable prevailing intrinsic properties, of that time/location.

Nonetheless, it may appear that, with the previous example, I closed the concept of art. However, that is not the case. Instead, I specified the theory of art that was in place from 18981906 in France among the Fauves; a specific historical and cultural context. With this in mind, an important idea can be illustrated. I previously stated that the set of intrinsic features that constitute a theory are isolated to their respective context; there can exist, simultaneously, more than one art theory. A prime example of this is the movement known as Symbolism. It originated in France, like Fauvism, and its time period is 1860 to 1910. This means that it was a movement occurring simultaneously with Fauvism; most importantly, however, is that it encompassed an art theory, different and existing alongside the art theory of the Fauves.

The movement was a revolt against naturalism and often considered to have been triggered by the Symbolist Manifesto of Jean Moréas, declaring that realism was an archaic model of art. ${ }^{15}$ Symbolism lacks a defined "stylistic tendency;” instead, symbolism represents more of a "general outlook." There was a slight preference for broad strokes of color, unmixed and pure, and flat forms but the only truly overarching characteristic was a familiarity in the content of the pieces. The artists rejected naturalism; there was instead a focus on the imagination, dreams, magic, mythology, and spirituality. An excellent description of the mindset

\footnotetext{
${ }^{15}$ See Janson (1995), 739.
} 
of the artists is from Anthony F. Janson's History of Art: "It reflected an intellectual and moral upheaval that rejected the modern world and its materialism in favor of irrational states of mind. A self-conscious preoccupation with decadence, evil, and darkness pervaded the artistic and literary climate. ${ }^{16}$ As stated, there was a lack of a consistent painting style with the movement; just common content. Thus, this illustrates the importance of context. The fantastical subject matter stands out against the naturalistic content of art that dominated France at the time. Even the Fauves had traditional/naturalistic content; just presented in an abstract fashion. If you were to view the works under the theory of art surrounding Symbolism without considering other works presented in that context, it would be difficult to, with a general lack of common intrinsic features, establish that the pieces fit under a single art theory. Context is indeed indispensable to any art theory.

Nonetheless, as I did with the Fauves, I detailed the theory of art. I specified the time, 1860-1910, and the place, France. I identified the historical and cultural context; that naturalistic themes dominated France for a long time and the Symbolist Manifesto of Jean Moréas resulted in a revolt. Finally, I detailed the characteristic intrinsic features, which was, for the theory surrounding Symbolism, a matter of content. It is important to emphasize that the sets of intrinsic features that constitute the theories of the Fauves and the Symbolists, and the extrinsic influences that led to their significance, are quite distinct even though they both subsisted in France during the same time. Thus, this demonstrates that more than one unique art theory can exist simultaneously; they are isolated to their historical and cultural context.

\section{V: Identifying Art and Defining Theories}

\footnotetext{
${ }^{16}$ See Janson (1995), 739-746.
} 
Thus far, I have stated my definition of art and provided evidence that there are dynamic, isolated theories that dictate what is considered art. Now, I want to address the following question: If a theory of art has been defined for a particular context, how can you determine if a work, produced prior to or after that theory was defined, is qualified for the status of candidate for appreciation? According to the definition I proposed, the theory of art for a given context is constituted of a specific set of intrinsic features. Thus, looking for the specified intrinsic features in a given work is how an individual determines whether, in that context, it should be a candidate for appreciation. While this is a rather straightforward approach, I think it is beneficial to consider an illustration. Consider a work that was produced in France between 1860 and 1910; the work is a painting portraying traditional subject matter. More specifically, the work is a portrait of a woman, whose face is half yellow and half peach, in a red and white dress. There is a green streak going from her hairline to her chin and her top-knotted hair is purple and black. The background is sectioned into orange, purple, and green. The brushstrokes are thick and the colors appear unmixed. Overall, the painting is crude and simplistic; certainly abstract. Now, I have surely chosen the specific context of presentation for a reason; I have already discussed two simultaneously existing art theories for the time and location. Of course, I am not implying that there were only two isolated art theories in France at the time but, for simplicity, I will consider this eventuality to make my point. The question is: Does this painting qualify as a candidate for appreciation when considering the context the work was presented in, the two theories of art that we know to subsist in that given context, and the work's intrinsic features? Well, the painting described is characterized by unmixed/pure colors, an unnatural use of color, a simplistic representation, and a subject matter that is traditional but abstract. Based on these details, the work described, which is actually Matisse's Portrait of Madame Matisse (1905), would be 
qualified for the status of candidate for appreciation in the context that it was presented in. This is because it fits under the theory of the Fauves; not the Symbolists due to the subject matter. We know the intrinsic features specified by the theory of art surrounding the Fauves and, from the description, the notable intrinsic features of the described work are the same. It is important to keep in mind that if the work had been presented in a different context, for instance one dominated by a theory including only "photograph-like" representational pieces, it would not be qualified to be a candidate for appreciation and, if it did acquire the status, would be failed art; again, context is key.

This approach bears a significant likeness to the so-called "family resemblance" theory. According to the family resemblance approach, there is a set of paradigm artworks. When determining whether or not a new work should be considered art, one compares it to paradigms to see if it is sufficiently similar. The similarities are noted to be "family resemblances." If the work in question is determined to exhibit a resemblance to the paradigm cases, or to a work that has already been acknowledged to resemble a paradigm case, that resemblance is sufficient for the work to be considered art. ${ }^{17}$ This is similar to the approach I proposed but there is, however, a key difference. I stated that we have to look for, in the work being considered, the intrinsic features that are specified by the relevant theory of art for the context that the work in question is or was being presented in. With the family resemblance theory, however, there has been no system proposed for deciding what is considered a relevant resemblance. The theory doesn't specify what features count as a “family resemblance.” For instance, consider a bucket of dirt

\footnotetext{
${ }^{17}$ The concept of family resemblances was offered by Wittgenstein, that through overlapping and crisscrossing resemblances we can group things, such as games, under a common heading, but he did not apply this philosophy to defining art. See Wittgenstein (1953). Morris Weitz, however, did apply this to art and my discussion of family resemblance is based on his work. See Weitz (1956).
} 
with paint poured over it and then a painting that is considered a paradigm case. With the family resemblance theory, the fact that paint was used in both works could be considered enough of a resemblance to justify the bucket of dirt being art; no standards have been set. Thus, my approach is significantly different. The intrinsic features of interest are specified for each theory of art; an individual knows exactly what she/he is looking for when determining whether a work is qualified to be a candidate for appreciation. ${ }^{18,19}$

I now want to address a different issue, an answer to the following question: How can a new art theory be established when the first works of that emerging theory, not reflecting current artmaking practices, are not considered art under the current theory? This, the problem of first art, isn't a problem at all. As I have stated, the reason for the conferral of the status of candidate for appreciation is the presence of the specific intrinsic features constituting the art theory for the context of interest. It is true that without the features a work should be regarded as non-art because they will not or should not have the status conferred upon them. However, as mentioned, a work can "unrightfully" acquire the status of candidate for appreciation, which is what prevents the stated matter from being a problem. The work will be considered art because of this conferral, but will fail, in light of the dominant theory of art in place, to be appreciated. Failed art is still art, however; thus, its respective intrinsic features can define a new theory of art.

It is important to mention that I have not stated at what point a set of works can be considered to warrant defining a new, isolated theory of art. It is easy to say, as I have done so far, that a new theory is defined when there is a notable degree of commonness between a set of

\footnotetext{
${ }^{18}$ In regard to recent works involving the family resemblance theory, Berys Gaut has proposed an account of art known as the cluster account of art, which draws considerable influence from it. See Gaut in Carroll (2000), 25-42 ${ }^{19}$ For further discussion on "Neo-Wittgensteinians," those influenced by Wittgenstein's Philosophical Investigations, and more specifically, Morris Weitz, see Carroll (1999), 206-217.
} 
works in regard to intrinsic features and the extrinsic influences that led to their significance. But there is the question of "What number of works justifies the defining of a new, isolated theory of art?” I will not provide an affirmative answer; I will not set a limit, upper or lower, on the amount of works required to define a theory of art. I will also not give a required number of similarities for a work to be considered for defining a theory of art; to be a "paradigm case.” I have stated that the theories are isolated to their location/time and associated historical/cultural backdrop; so there can exist, simultaneously, more than one specific art theory. If I had not allowed for this, a number might have been needed; it would have to be the dominant theory, the theory with the highest number of works fitting under it, that was considered relevant and everything not fitting within that theory would be non-art or failed art. However, because more than one theory may exist simultaneously, anyone can actually define an isolated theory of art; regardless of the number of pieces included. This doesn't mean, however, that the works included will not be considered failed art in light of the dominant theories for the respective time/location; a work can be art in one context with its relevant art theory and failed art in another.

There is another question to consider; "What is the required degree of similarity, between the set of intrinsic features found in a work and those specified by the relevant theory of art, for the work in question to be qualified for the status of candidate for appreciation?” It is easy when the work being presented contains most or all of the intrinsic features specified by the relevant theory to state that the work is qualified to be a candidate for appreciation. However, it is when a work is questionable, only having a slight resemblance to the works that defined the theory in the first place, that whether a work should have the status is uncertain. I will not specify a number of common intrinsic features, found in a work and those specified by a given theory, required for a 
work to be considered for the status of candidate for appreciation. Instead, I will rely on the historical narration approach formulated by Noel Carroll to provide a means for determining if a work is sufficiently similar.

The historical narration approach is concerned with a scenario comparable to the one described above; when a work is presented with the intention of it being considered art but that work does not wholly meet society's current expectations about what art is. In his view, a narrative must be told that connects the work in question with preceding artmaking contexts. These narratives have three parts- a beginning, a complication, and an end. The beginning involves the acknowledgment and description of the current/relevant artmaking context. Thus, when considering my theory, this would be the portion of the narrative where an individual described the relevant theory of art in place. The complication is where the artist gives their own assessment of the artworld. This assessment should involve the motivation behind the work being presented. For instance, if the work in question is presented with the intention of fitting under a certain theory of art, the assessment of the artworld surrounding that theory should be that it is unproblematic. The motivation would be to endorse current artmaking practices. The "end" of the historical narrative is the presentation of the work. ${ }^{20}$ So, overall, the purpose of the historical narratives is to fill the gap between the work being presented and the current traditions. Therefore, in light of my theory, the purpose would be to fill the gap between the work being presented and the relevant theory of art.

To illustrate how the historical narration approach can be of use, consider two works presented in the artworld. I will designate one piece "work A" and the other "work B." The pieces are not equal in regard to how many of the specific intrinsic features from the relevant art

${ }^{20}$ See Carroll, Identifying Art, in Yanal (1994), 3-39. 
theory they include; "work A" has them all and "work B" has only a few. However, the artists of the works both had the intentions of working under the current theory of art. I discussed that the means for identifying works of art, when a theory has been defined, is to look for the relevant intrinsic features, specified by the relevant art theory for the time and location. When dealing with a case such as "work A," the decision is clear; the work is qualified for the status of candidate for appreciation. It is when dealing with cases such as "work B," however, that the question of how many relevant intrinsic features, despite the artist's intention to reflect current artmaking practices, warrants the conferral. So, consider the formulation of a historical narrative. There is a beginning, complication, and end. The beginning would involve describing the artmaking practices, the theory, of the context that the work is being presented in. This would be followed by the complication. The presenter would give their own assessment of the artworld. It would be, because they intended for their work to fit within the current theory, assessed as satisfactory. Thus, the assessment would involve discussing why the current practices are sufficient, what the motivation was for their contribution to the current practices, and why the work being presented was chosen as the suitable contender to further support current practices. The "end" of the historical narrative is the presentation of the work. The construction of such a narrative would demonstrate that the artist was working under a sound interpretation of general understandings of the purpose(s) of art for their particular culture. More importantly, it would establish that their work is an intelligible outcome of current practices. As stated by Carroll, "in order to counter the suspicion that $x$ is not a work of art, the defender of $x$ has to show how $x$ emerged intelligibly from acknowledged practices via the same sort of thinking, acting, decisionmaking, and so on that is already familiar in the practice."${ }^{21}$ With this in mind, coupled with the artists expressed intention of reflecting the relevant theory of art as well as the visible features,

\footnotetext{
${ }^{21}$ See Carroll, Identifying Art, in Yanal (1994), 17.
} 
few but existent, seen in the work that validate this intention, the conferral of the status of candidate for appreciation would be warranted.

\section{VI: Conclusion}

To summarize what has been accomplished throughout this paper, I have proposed a new account of art using the institutional theory of art as a framework. This account of art is, of course, the result of proposing a modification to George Dickie's theory in response to the criticism that the status of candidate for appreciation is arbitrarily conferred. The modification is that the conferral of the status of candidate for appreciation is not random. That there are dynamic, isolated art theories, stipulating particular sets of intrinsic feature, dictating what is suited for the status of candidate for appreciation for a given context. These art theories are proposed in retrospect. They are defined after determining what the significant intrinsic features were for a given context at a particular time in history and the extrinsic influences that prompted their elevation. The theories, as stated, are isolated, to the historical and cultural backdrop of a particular time and location, and they are also dynamic. This means they are able to change as a result of societal forces influencing the artmaking practices of society; society dictates what intrinsic features are found to be significant. I also discussed how looking for the specified intrinsic features is a reliable method for determining what works, presented to the artworld prior to or after the detailing of a particular art theory, are qualified for the status of candidate for appreciation; the sets of intrinsic features that are of interest vary from theory to theory, which

are unique to each context. Finally, I argued that the historical narration approach of Noel Carroll can be utilized to tackle tough cases in which it is questionable whether a work fits under an existing theory of art. 
With this in mind, I want to recap what my goal was; to detail a new theory that brings us closer to answering the question "What is art?” in its entirety. My theory suggests that there are individual art theories, constituted of specific sets of intrinsic features, which dictate what art is for a given historical and cultural backdrop at particular time and location. Thus, my theory does not attempt to provide an overarching, universal answer to the question. Instead, my approach strives to provide an answer for each unique context. Thus, it is the summation or compilation of these art theories for the different contexts that serves as my proposed answer to the age-old question of "What is art?" 


\section{Works Cited}

Cahn, Steven M., and Aaron Meskin, eds. Aesthetics: A Comprehensive Anthology. Malden, MA: Blackwell Pub., 2008.

Carroll, Noël. Philosophy of Art: A Contemporary Introduction. London: Routledge, 1999.

Carroll, Noël. Theories of Art Today. Madison: University of Wisconsin, 2000.

Danto, Arthur. "The Transfiguration of the Commonplace." Journal of Aesthetics and Art Criticism 33.2 (1974): 139-48.

Dickie, George. Aesthetics: An Introduction. Indianapolis: Pegasus, 1971.

Dickie, George. Art and the Aesthetic: An Institutional Analysis. Ithaca, NY: Cornell UP, 1974.

Dickie, George. The Art Circle: A Theory of Art. New York: Haven, 1984.

Dickie, George. "Defining Art." American Philosophical Quarterly 6.3 (1969): 253-56.

Janson, Horst. History of Art. Ed. Anthony Janson and Joanne Greenspune. 5th ed. Englewood Cliffs: Prentice Hall, 1995.

Rhodes, Colin. Outsider Art: Spontaneous Alternatives. New York: Thames \& Hudson, 2000.

Smith, Paul, and Carolyn Wilde, eds. A Companion to Art Theory. Malden: Blackwell, 2002.

Turner, Jane, ed. From Expressionism to Post-modernism: Styles and Movements in 20th-century Western Art. New York: Groveart, 2000.

Warburton, Nigel. The Art Question. London: Routledge, 2003.

Weitz, Morris. "The Role of Theory in Aesthetics." Journal of Aesthetics and Art Criticism 15.1 (1956): 2735.

Wittgenstein, Ludwig. Philosophical Investigations. Oxford: B. Blackwell, 1953.

Yanal, Robert J., ed. Institutions of Art. University Park: Pennsylvania State UP, 1994. 